\title{
The Cox maze IV procedure: Predictors of late recurrence
}

\author{
Ralph J. Damiano, Jr, MD, Forrest H. Schwartz, BA, Marci S. Bailey, RN, MSN, Hersh S. Maniar, MD, \\ Nabil A. Munfakh, MD, Marc R. Moon, MD, and Richard B. Schuessler, PhD
}

\begin{abstract}
Objectives: The Cox maze III procedure achieved high cure rates and became the surgical gold standard for the treatment of atrial fibrillation. Because of its invasiveness, a more simplified ablation-assisted procedure, the Cox maze IV procedure, has been performed at our institution since January 2002. The study examined multiple preoperative and perioperative variables to determine predictors of late recurrence.
\end{abstract}

\begin{abstract}
Methods: Data were collected prospectively on 282 patients who underwent the Cox maze IV procedure from January 2002 through December 2009. Forty-two percent of patients had paroxysmal and 58\% had either persistent or long-standing persistent atrial fibrillation. All patients were available for follow-up. Follow-up included electrocardiograms in all patients. Since 2006, 24-hour Holter monitoring was obtained in $94 \%$ of patients at 3, 6, and 12 months. Data were analyzed by means of logistic regression analysis at 12 months, with 13 preoperative and perioperative variables used as covariates.
\end{abstract}

Results: Sixty-six percent of patients had a concomitant procedure. After an ablation-assisted Cox maze procedure, the freedom from atrial fibrillation was $89 \%, 93 \%$, and $89 \%$ at 3, 6, and 12 months, respectively. The freedom from both atrial fibrillation and antiarrhythmic drugs was $63 \%, 79 \%$, and $78 \%$ at 3,6 , and 12 months, respectively. The risk factors for atrial fibrillation recurrence at 1 year were enlarged left atrial diameter $(P=.027)$, failure to isolate the entire posterior left atrium $(P=.022)$, and early atrial tachyarrhythmias $(P=.010)$.

Conclusions: The Cox maze IV procedure has a high success rate at 1 year, even with improved follow-up and stricter definitions of failure. In patients with large left atria, there might be a need for more extensive size reduction or expanded lesion sets. (J Thorac Cardiovasc Surg 2011;141:113-21)

The Cox maze procedure was introduced in 1987 at our institution for the treatment of atrial fibrillation (AF) by Dr James L. Cox. ${ }^{1}$ The first 2 iterations of this procedure were abandoned because of a high incidence of pacemaker implantation and technical difficulty. The final version introduced was the Cox maze III procedure, and it remained the gold standard for the treatment of AF for more than a decade. In a follow-up study of 198 consecutive patients from our institution, the overall freedom from symptomatic AF was $97 \%$ with a mean follow-up of $5.4 \pm 2.9$ years. $^{2}$ Although this was a high success rate, the patients did not undergo rigorous follow-up by present standards. Most of

\footnotetext{
From the Division of Cardiothoracic Surgery, Washington University School of Medicine, Barnes-Jewish Hospital, Saint Louis, Mo.

Supported in part by National Institutes of Health grants R01 HL032257-21 and F32 HL082129-02.

Disclosures: Dr Ralph J. Damiano, Jr, is a consultant for AtriCure, Inc; Medtronic, Inc; and ATS Medical, Inc. Dr Richard B. Schuessler receives research funding from AtriCure, Inc; Medtronic, Inc; and Estech. Dr Hersh S. Maniar is a consultant for nContact Surgical and Estech.

Read at the 90th Annual Meeting of The American Association for Thoracic Surgery, Toronto, Ontario, Canada, May 1-5, 2010.

Received for publication May 3, 2010; revisions received July 13, 2010; accepted for publication Aug 2, 2010.

Address for reprints: Ralph J. Damiano, Jr, MD, Washington University School of Medicine, Barnes-Jewish Hospital, Suite 3108 Queeny Tower, 1 Barnes-Jewish Hospital Plaza, Saint Louis, MO 63110 (E-mail: damianor@wustl.edu).

$0022-5223 / \$ 36.00$

Copyright (c) 2011 by The American Association for Thoracic Surgery

doi:10.1016/j.jtcvs.2010.08.067
}

the rhythms were documented only by means of a mailed questionnaire or telephone interview. Very few of the patients had any monitoring more than an electrocardiogram to document their rhythm. Moreover, the most recent consensus statement on ablation for AF has proposed that success be defined as freedom from AF, atrial tachycardia, or atrial flutter (atrial tachyarrhythmias [ATAs]) off of antiarrhythmic drugs. ${ }^{3}$ In our previous report success was considered simply freedom from symptomatic AF. Our results with the original cohort of the cut-and-sew Cox maze III procedure showed that $27 \%$ of patients were taking antiarrhythmic drugs at the last follow-up. ${ }^{2}$

In 2002, a new iteration of the Cox maze procedure was introduced, termed the Cox maze IV procedure, which replaced most of the incisions with linear lines of bipolar radiofrequency ablation (Figure 1). ${ }^{4}$ Initially, the procedure had only a single inferior connecting ablation line between the pulmonary veins in an attempt to better preserve left atrial function. However, a second connecting lesion superiorly was added several years later to anatomically isolate the entire posterior left atrium (termed the box lesion set) in an attempt to improve early and late results. At this time, we also adopted a more rigorous follow-up of the patients, with all patients having either electrocardiographic or 24-hour Holter monitoring at 3, 6, and 12 months and annually thereafter. An examination of predictors of failure after the Cox maze procedure was published by our group in 


\section{Abbreviations and Acronyms \\ $\mathrm{AF}=$ atrial fibrillation \\ ATA $=$ atrial tachyarrhythmia}

$2005 .{ }^{5}$ However, the great majority of patients in this series underwent a Cox maze III procedure. As stated above, the definition of failure was not rigorous, and patients rarely had electrocardiographic monitoring. The only risk factors for late recurrence of $\mathrm{AF}$ were duration of preoperative $\mathrm{AF}$ and earlier version of the Cox maze procedure, with both the Cox maze I and II procedures having higher failure rates than the Cox maze III procedure.

To better define predictors of failure in the modern era, this study was designed to look at our experience with the Cox maze IV procedure alone, in which follow-up has been more rigorous and intensive, with 24-hour Holter monitoring obtained in the majority of patients at 3, 6, and 12 months. Moreover, success was defined only as patients being both free of ATAs and off antiarrhythmic drugs. A previous report from our institution has shown that this is important to accurately define criteria for successful outcome. ${ }^{6}$ In this study our prospective database was reviewed to evaluate the predictors of late ATA recurrence in 282 consecutive patients who underwent a Cox maze IV procedure.

\section{MATERIALS AND METHODS}

From January 2002 through December 2009, 282 patients underwent a Cox maze IV procedure for AF. All procedures were performed during cardiopulmonary bypass. The right atrial lesion set was done on the beating heart, whereas the left atrial lesions were performed during cardioplegic arrest. As described previously, 2 small atriotomies were performed. The rest of the incisions of the Cox maze III procedure were replaced with linear ablation lines by using either the AtriCure (West Chester, Ohio) or Medtronic (Minneapolis, Minn) bipolar radiofrequency clamp. At the tricuspid and mitral valve annuli, cryoablation was used in the vast majority of cases. In a small number of cases, a unipolar ablation pen, either the AtriCure Max1 or the Medtronic Cardioblate XL pen, was used. The coronary sinus was ablated both with the bipolar clamp and with epicardial cryoablation.

In $245(87 \%)$ patients electrical pulmonary vein isolation was confirmed by pacing, demonstrating exit block from each of the pulmonary veins. Of the 37 patients who did not have pacing thresholds or exit block checked, 12 patients had a suspicious left atrial appendage clot seen, and cardioversion could not be performed. Thirteen patients remained in AF despite cardioversion or were in heart block. Initially, we only performed a single inferior connecting lesion between the pulmonary veins, leaving most of the posterior left atrium in electrical continuity with the remainder of the atrial myocardium. In 2005, a second superior connecting lesion was added (the box lesion set) to anatomically isolate the entire posterior left atrium (Figure 1). Pacing was not performed to confirm the electrical isolation of the posterior left atrium. Although the majority of patients underwent their procedures through a median sternotomy, 29 had a less-invasive right minithoracotomy approach. These patients had an identical lesion set that has been previously described. ${ }^{7}$ However, the left atrial appendage was oversewn from the endocardial surface instead of being amputated. Of the entire group, $95(34 \%)$ patients underwent a stand-alone maze procedure. The majority underwent concomitant surgical procedures, with the most common being either a mitral valve procedure or coronary artery bypass grafting (Table 1). AF was defined as paroxysmal, persistent, or longstanding persistent per recent guidelines. ${ }^{3}$ The patients' clinical profiles and postoperative outcomes were recorded prospectively in a longitudinal database containing 386 variables. All patients were available for followup, and every patient had a minimum 3-month follow-up.

In this series patients were started on class I or III antiarrhythmic drugs and warfarin before hospital discharge. If they were in sinus rhythm at 2 months, the antiarrhythmic drugs were discontinued. At 3 months, 24-hour Holter monitoring and echocardiography were performed. If patients had no evidence of ATAs or atrial stasis by means of echocardiography, their anticoagulation was stopped.

Follow-up was conducted by obtaining electrocardiograms for all patients at 3,6, and 12 months. Since 2006, when the new guidelines were first circulated, 24-hour Holter monitoring or pacemaker interrogation was obtained in $94 \%$ of patients. Late recurrence was defined as any episode of AF, atrial flutter, or atrial tachycardia that lasted more than 30 seconds. Any patient requiring an interventional procedure after 3 months was deemed a permanent failure. Patients were only considered to be a success if they were both off antiarrhythmic drugs and free of ATAs. For the purpose of this analysis, we defined antiarrhythmic drugs as either Vaughan-Williams type I or III. $\beta$-Blockers or calcium-channel blockers were not considered to be antiarrhythmic drugs. Only patients who were alive at 12 months were included in the analysis. This study was approved by the Washington University School of Medicine Institutional Review Board. Informed consent and permission for release of information were obtained from each participant.

Continuous variables are expressed as means \pm standard deviations unless otherwise specified, and categorical data are expressed as counts and proportions. Comparisons were done with paired, 2-tailed $t$ tests for means of normally distributed continuous variables. Either the $\chi^{2}$ or Fisher's exact test was used to compare categoric data. Thirteen preoperative and perioperative variables were evaluated in a univariate analysis to identify potential predictors of late ATA recurrence. These included age, sex, type and duration of AF, New York Heart Association class, type of bipolar radiofrequency device, left ventricular ejection fraction, failed catheter ablation, left atrial diameter, pulmonary vein box versus nonbox lesion set, concomitant versus stand-alone Cox maze procedure, early ATAs (within the first postoperative month), and early postoperative pacemaker implantation within the first 90 days. Significant covariates on univariate analysis $(P \leq .10)$ or covariates deemed clinically relevant based on our experience were entered into a multivariate binary logistic regression analysis. All data analyses were performed with SPSS software (SPSS 11.0 for Windows; SPSS, Inc, Chicago, Ill).

\section{RESULTS \\ Demographics}

The mean age of patients undergoing a Cox maze IV procedure was $63 \pm 12$ years (range, 23-83 years; Table 2). There were 177 men and 105 women. Forty-two percent of patients were in paroxysmal AF. Ten percent were in persistent and $48 \%$ were in long-standing persistent AF. The median duration of AF was 3.7 years. Most patients $(66 \%)$ underwent concomitant cardiac operations. Among patients undergoing a stand-alone Cox maze procedure, $46 \%(\mathrm{n}=44)$ were referred for failure of medical therapy, $40 \%(\mathrm{n}=38)$ had catheter ablation failure, and $14 \%$ $(\mathrm{n}=13)$ were referred for either a stroke or transient ischemic attack. In the entire series $52(18 \%)$ patients had previous catheter ablation failure.

In the concomitant group half of the patients underwent mitral or mitral plus tricuspid valve surgery (93 [50\%] 




\section{A}

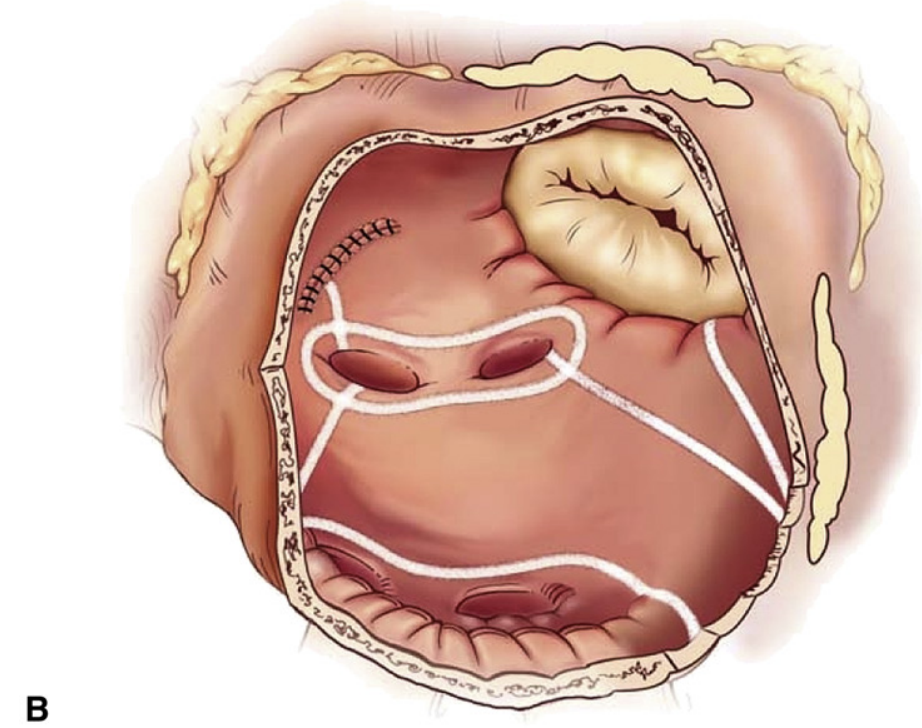

FIGURE 1. A, Right atrial lesion set of the Cox maze IV procedure. B, Left atrial lesion set of the Cox maze IV procedure.

patients). Forty-three $(23 \%)$ patients underwent coronary bypass grafting with or without mitral valve repair. In 29 $(16 \%)$ patients the primary indication was for aortic valve replacement. The rest of the patients underwent more complicated concomitant procedures (Table 1).

\section{Perioperative Results}

The overall operative mortality was $2 \%$ in the entire series and $1 \%$ in the stand-alone Cox maze cohort. The mean aortic crossclamp time for patients undergoing a Cox maze procedure with concomitant surgical interven- tion was $96 \pm 27$ minutes. This was shorter in patients undergoing a lone Cox maze procedure ( $43 \pm 15$ minutes). Previous published work from our group has shown that these times were significantly shorter when compared with our experience with the traditional cut-and-sew Cox maze III procedure. ${ }^{8}$ The median length of stay was 9 days (range, 4-73 days). Eleven percent of patients had major perioperative complications $(\mathrm{n}=31)$. These complications include reoperation for bleeding $(n=14)$, intraaortic balloon pump placement $(n=9)$, stroke $(n=5)$, renal failure $(\mathrm{n}=12)$, and mediastinitis $(\mathrm{n}=1)$. Seven patients 
TABLE 1. Concomitant cardiac procedures $(n=187)$

\begin{tabular}{lrr}
\hline & No. & \% \\
\hline CM + mitral valve procedure & 79 & 42 \\
CM + mitral valve + tricuspid procedure & 14 & 7 \\
CM + CABG & 26 & 14 \\
CM + CABG + mitral valve procedure & 17 & 9 \\
CM + aortic valve procedure & 16 & 9 \\
CM + aortic valve + CABG & 13 & 7 \\
CM + mitral valve + aortic valve procedure & 5 & 3 \\
CM + septal myectomy \pm additional procedures & 7 & 4 \\
CM + other procedures & 10 & 5 \\
\hline$C M$, Cox maze procedure; CABG, corary artery byss & &
\end{tabular}

$C M$, Cox maze procedure; $C A B G$, coronary artery bypass grafting.

experienced more than 1 major perioperative complication. Early postoperative atrial arrhythmias were documented in $53 \%$ of patients $(n=150)$. These dysrhythmias were usually transient, and most resolved over the first month. Early permanent pacemaker placement within 30 days of the operation occurred in $9 \%(n=24)$ of patients. A large majority of these patients had documented evidence of sick sinus syndrome preoperatively.

\section{Late Follow-up}

Follow-up was available in all patients. After a Cox maze IV procedure, the freedom from ATAs was $89 \%, 93 \%$, and $89 \%$ at 3, 6, and 12 months, respectively (Figure 2). The

TABLE 2. Patients' characteristics

\begin{tabular}{|c|c|c|c|c|}
\hline \multirow[b]{2}{*}{ Variables } & \multicolumn{2}{|c|}{$\begin{array}{l}\text { Stand-alone } \\
\text { CM }(\mathbf{n}=95)\end{array}$} & \multicolumn{2}{|c|}{$\begin{array}{l}\text { Concomitant } \\
\text { CM }(n=187)\end{array}$} \\
\hline & No. & $\begin{array}{c}\% \text { or } \\
\text { (range) }\end{array}$ & No. & $\begin{array}{l}\% \text { or } \\
\text { (range) }\end{array}$ \\
\hline \multicolumn{5}{|l|}{ Preoperative } \\
\hline Age $(y)$ & $56 \pm 10$ & $28-77$ & $66 \pm 12$ & $23-83$ \\
\hline Male sex & 73 & 77 & 104 & 56 \\
\hline \multicolumn{5}{|l|}{ AF duration (y) } \\
\hline Mean & $7.5 \pm 6.7$ & $0.1-28.0$ & $5.8 \pm 7.9$ & $0.1-46.0$ \\
\hline Median & 6.0 & & 3.0 & \\
\hline Paroxysmal AF & 29 & 31 & 89 & 48 \\
\hline NYHA class 3 or 4 & 19 & 20 & 141 & 75 \\
\hline Sleep apnea & 18 & 19 & 30 & 16 \\
\hline $\begin{array}{l}\text { History of failed } \\
\text { catheter ablation }\end{array}$ & 38 & 40 & 14 & 7 \\
\hline \multicolumn{5}{|l|}{ Operative } \\
\hline Mean CCT (min) & $43 \pm 15$ & & $96 \pm 27$ & \\
\hline Box lesion around PVs & 73 & 77 & 151 & 81 \\
\hline LA diameter $(\mathrm{cm})$ & $4.8 \pm 1.1$ & $2.5-8.0$ & $5.5 \pm 1.2$ & $2.9-10.0$ \\
\hline \multicolumn{5}{|l|}{ Postoperative } \\
\hline $\begin{array}{l}\text { Operative mortality } \\
\qquad(\leq 30 \mathrm{~d})\end{array}$ & 1 & 1 & 6 & 3 \\
\hline Early ATA & 42 & 44 & 108 & 58 \\
\hline Median hospital LOS (d) & 7 & $4-53$ & 10 & $4-73$ \\
\hline
\end{tabular}

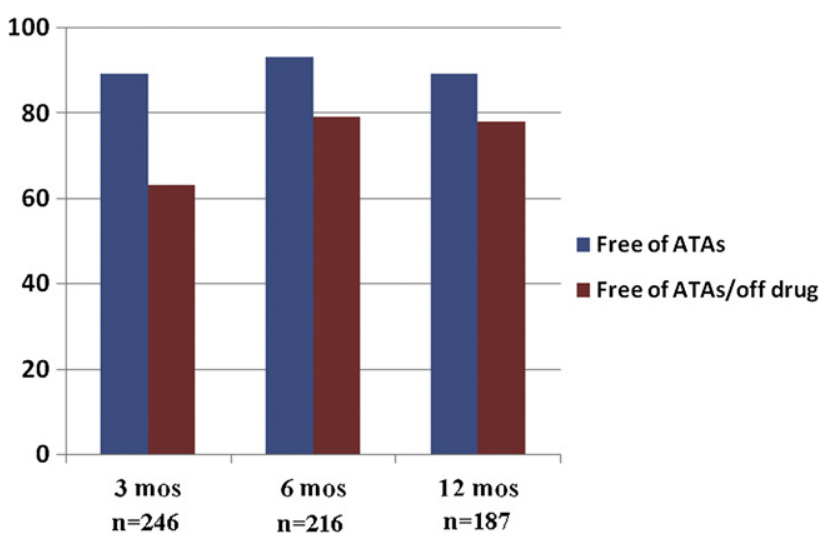

FIGURE 2. Freedom from atrial tachyarrhythmias (ATAs) with and without antiarrhythmic drugs at 3,6, and 12 months with number of patients at risk.

freedom from both antiarrhythmic drugs and arrhythmias was $63 \%, 79 \%$, and $78 \%$ as 3,6 , and 12 months, respectively. Of the $70 \%(\mathrm{n}=178)$ with prolonged monitoring, $92 \%(\mathrm{n}=164)$ were free of ATAs and $79 \%(\mathrm{n}=141)$ were free of ATAs and off antiarrhythmic medications. There was no difference in the late success rate for patients with paroxysmal versus persistent or long-standing $\mathrm{AF}$ $(P=.378)$. There also was no difference in success rates for patients undergoing stand-alone versus concomitant procedures $(P=.361)$. Of the 16 patients with ATAs at 6 months, 9 patients had recurrent AF, 5 patients had atrial flutter, and 1 patient had atrial tachycardia. At 12 months, 15 patients had recurrent $\mathrm{AF}$, and 5 patients had atrial flutter.

\section{Recurrence of ATAs}

A univariate analysis of preoperative and perioperative variables was performed to determine potential predictors of late ATA recurrence. The only significant predictors of recurrence on univariate analysis were the absence of a box lesion set, increasing left atrial diameter, and early postoperative ATAs. The following variables were entered into a multivariate logistic regression to determine risk factors for failure after a Cox maze procedure: age, AF duration, box versus nonbox lesion set, left atrial diameter, early postoperative ATAs, and early pacemaker implantation. Left atrial size was a significant predictor of failure, with an odds ratio of 1.42 (Table 3 ). The probability of $\mathrm{AF}$ recurrence increased with increasing left atrial diameter (Figure 3). The failure to anatomically isolate the entire posterior left atrium (nonbox lesion set) was also predictive of failure with a $P$ valve of .022 . Finally, patients with early postoperative ATAs were significantly more likely to fail, with an odds ratio of 3.05. As opposed to our prior publication, duration of preoperative AF was not a predictor of failure. Other variables that were not predictors of failure at 12 months by means of multivariate analysis included age and early pacemaker implantation. 
TABLE 3. Multivariate logistic regression analysis of risk factors for failure after the Cox maze IV procedure (38/187 [20.3\%])

\begin{tabular}{lcccc}
\hline \multicolumn{1}{c}{ Variable } & No. & Odds ratio & $\mathbf{9 5} \%$ CI & $\boldsymbol{P}$ value \\
\hline Left atrial diameter & 187 & 1.420 & $1.04-1.94$ & $\mathbf{. 0 2 7}$ \\
$\begin{array}{l}\text { Box lesion set around } \\
\text { pulmonary veins }\end{array}$ & 137 & 0.382 & $0.167-0.871$ & $\mathbf{. 0 2 2}$ \\
$\begin{array}{l}\text { Early atrial tachyarrhythmias } \\
C I \text { Confidence interval. }\end{array}$ & 96 & 3.020 & $1.079-8.455$ & $\mathbf{. 0 1 0}$ \\
\hline
\end{tabular}

CI, Confidence interval.

\section{DISCUSSION}

The Cox maze procedure has been the most successful surgical treatment for $\mathrm{AF}^{2,9-11}$ Our institution has had the longest experience with this operation and has maintained a prospective database over the last 2 decades following all of our patients. Although we have published extensively on our series, our prior reports have generally not followed recent guidelines in terms of recommended follow-up or definition of failure. ${ }^{3}$ In this report of more than 280 patients, follow-up was more rigorously collected, with a strict definition of $\mathrm{AF}$ recurrence consistent with the recent consensus statement. Moreover, this report only included patients undergoing an ablation-assisted Cox maze IV procedure. This is more relevant to modern practice because we have not performed a cut-and-sew maze procedure in 8 years. Furthermore, with the more rigorous follow-up and definition of failure, the present study provides a much more accurate representation of late recurrence, allowing for a better elucidation of preoperative and postoperative risk factors leading to failure of the Cox maze procedure.

In this case series the Cox maze procedure had excellent results at 1 year, with $89 \%$ of patients free from atrial dysrhythmias and $78 \%$ free of arrhythmias and off drugs. In patients undergoing a stand-alone procedure, the success rates were $91 \%$ and $74 \%$, respectively. This compares favorably with our historical data from the Cox maze III procedure, in which only symptomatic follow-up was obtained. ${ }^{2}$ In our previous report $80 \%$ of patients undergoing a stand-alone procedure were both free of $\mathrm{AF}$ and antiarrhythmic drugs at last follow-up. In the concomitant group $73 \%$ of patients were in sinus rhythm and off antiarrhythmic drugs at last follow-up. Although follow-up in our previous report was longer, virtually none of these patients had electrocardiographic or Holter monitoring to determine their actual heart rhythm. It is heartening to see similar numbers obtained with more aggressive follow-up and a stricter definition of recurrent ATAs. It also is important to remember that in the current era, we are operating on a sicker cohort of patients with higher incidences of congestive heart failure and other comorbidities who undergo more complex concomitant operations. Because of the difficulty and time-consuming nature of the traditional cut-and-sew Cox maze III procedure, principally low-risk patients were historically offered concomitant surgery.

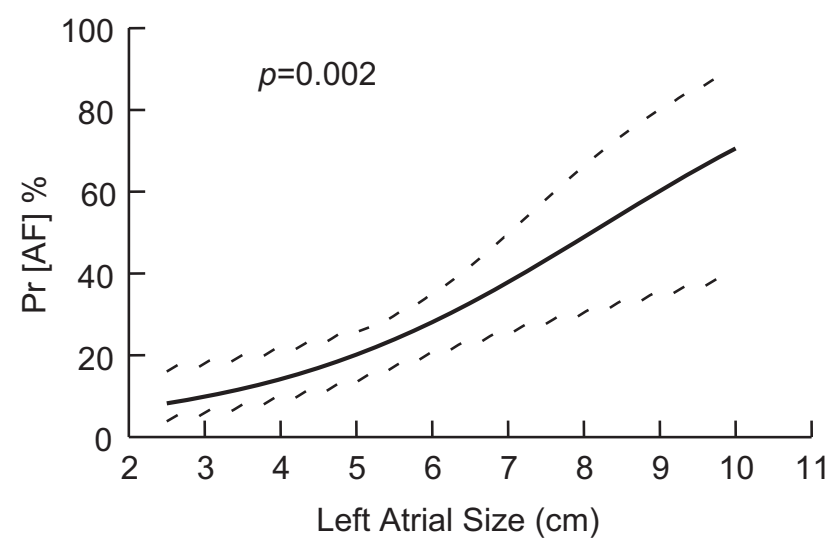

FIGURE 3. Relationship between left atrial size and probability of atrial fibrillation $(\operatorname{Pr}[A F])$ recurrence.

There were 3 risk factors for recurrent atrial arrhythmias after the Cox maze IV procedure using our multivariate logistic regression analysis. These included left atrial size, failure to anatomically isolate the entire posterior left atrium, and early ATAs (Table 3). Increasing left atrial size was a significant risk factor for failure (Figure 2). This agrees with previous reports in the literature. ${ }^{12-14}$ This is not surprising because our laboratory has shown that as atrial surface area increases, there is a higher incidence of inducible $\mathrm{AF} .{ }^{15}$ In this study the probability of recurrent tachyarrhythmias exceeded $50 \%$ once left atrial size was greater than $8 \mathrm{~cm}$. Although it has been our policy to perform a left atrial reduction in left atria of $7 \mathrm{~cm}$ or larger, this added procedure obviously was not successful in preventing recurrence. Patients with large left atria need to be adequately counseled on their high risk for failure. In this group the value of concomitant $\mathrm{AF}$ ablation remains unclear, and surgeons should be cautious adding the Cox maze procedure if there is any chance that it might increase perioperative risk. Our data do suggest the need for either a more aggressive left atrial reduction or a more extensive ablation lesion set in this patient population.

Another risk factor for recurrence of ATAs was the failure to anatomically isolate the entire posterior left atrium. Our initial version of the Cox maze procedure involved only 1 inferior connecting lesion between the pulmonary vein isolations, thus leaving most of the posterior left atrium in continuity with the rest of the left atrium. ${ }^{4}$ In 2005 , we began to isolate the entire posterior left atrium by making 2 connecting lesions, one between the left and right inferior pulmonary veins and one between the superior pulmonary veins. This significantly increased our drug-free success rates in a prior report. ${ }^{6}$ In this larger series of patients, this still remained a significant risk factor for recurrence. It is our present recommendation that all patients undergoing surgical ablation for AF have their entire posterior left atrium anatomically isolated. This finding in surgical 
patients agrees with data from the electrophysiology laboratory, in which wide-area circumferential ablation involving most of the posterior left atrium has been shown to be more effective than targeting only the pulmonary veins. ${ }^{3,16,17}$

A final risk factor for failure was patients who experienced early tachyarrhythmias. This does not agree with a prior report from our group, but it is intuitive that these patients would have a higher failure rate. ${ }^{18}$ Early ATAs were managed aggressively, first with chemical and then electrical cardioversion if drug therapy was unsuccessful. Cardioversion was usually performed between 1 and 4 weeks postoperatively. The high incidence of early ATAs in this group is likely due to a number of reasons. All of the patients had preoperative AF, usually of long duration, and had already developed the appropriate substrate required to sustain this arrhythmia. Also, previous work from our laboratory has shown that early postoperative $\mathrm{AF}$ is due to myocardial inflammation. ${ }^{19}$ The multiple atrial ablations likely cause a robust inflammatory response. It is not known whether a more aggressive attempt to prevent early ATAs would improve late success, but this seems unlikely. It is more probable that early ATAs might be a marker of a more advanced pathology of the atrial substrate, and this would logically make these patients more prone to late recurrence.

Numerous factors were not found to be associated with late failure on univariate analysis, including sex, age, New York Heart Association class, type of bipolar device, type or duration of AF, ejection fraction, failed catheter ablation, or postoperative pacemaker implantation. It is interesting that in this study preoperative AF duration was not shown to be a significant predictor of late failure. This contradicts our prior report evaluating mainly the Cox maze III procedure. ${ }^{5}$ This might be a result of patients being referred earlier for $\mathrm{AF}$ ablation, as indicated by a significantly lower median duration of $\mathrm{AF}$ in this series (3.7 years) compared with our previous report (5 years). It might be also due to the fact that in patients with concomitant structural heart disease, who comprised $66 \%$ of the patients in this series but only $41 \%$ of patients in our prior report, the effect of prolonged duration of $\mathrm{AF}$ is overwhelmed by the electrical remodeling and atrial dilatation caused by congestive heart failure and valvular heart disease. ${ }^{5}$

The study has several limitations. Although follow-up has improved considerably over time, there are still patients who did not have 24-hour Holter monitoring, and thus the actual failure rate might be underestimated. ${ }^{20}$ However, compared with previous reports in the literature, this patient cohort has been well monitored, and no patient was lost to follow-up. Another limitation of this report was that the precise mechanism of ATA recurrence was not defined in the majority of patients. The question remains unanswered whether this was due to technical difficulty in performing a complete Cox maze lesion set or to inherent atrial pathol- ogy. Because we have been performing this procedure for more than 2 decades, it is unlikely that the failures were due to an inappropriately performed lesion set. It is possible that there were recurrences due to bridging of cardiac conduction over the linear scars formed by the bipolar devices, but this phenomenon has not been demonstrated in patients. It also is possible that some of the lines of ablation were not actually transmural because only the efficacy of pulmonary vein isolation was tested. In the future, our hope is to perform noninvasive electrocardiographic imaging to better define the mechanisms of failure and allow us to develop strategies to improve surgical success rates.

In conclusion, failure to isolate the entire posterior left atrium and increasing left atrial diameter were the 2 risk factors for failure that can be modified by surgeons. In patients with a large left atrium, this study would suggest that efforts to improve left atrial reduction procedures or perform more extensive lesion sets are warranted.

\section{References}

1. Cox JL, Schuessler RB, D'Agostino HJ Jr, et al. The surgical treatment of atrial fibrillation. III. Development of a definitive surgical procedure. J Thorac Cardiovasc Surg. 1991;101:569-83.

2. Prasad SM, Maniar HS, Camillo CJ, et al. The Cox maze III procedure for atrial fibrillation: long-term efficacy in patients undergoing lone versus concomitant procedures. J Thorac Cardiovasc Surg. 2003;126:1822-8.

3. Calkins H, Brugada J, Packer DL, et al. HRS/EHRA/ECAS expert Consensus Statement on catheter and surgical ablation of atrial fibrillation: recommendations for personnel, policy, procedures and follow-up. A report of the Heart Rhythm Society (HRS) Task Force on catheter and surgical ablation of atrial fibrillation. Heart Rhythm. 2007;4:816-61.

4. Gaynor SL, Diodato MD, Prasad SM, et al. A prospective, single-center clinical trial of a modified Cox maze procedure with bipolar radiofrequency ablation. J Thorac Cardiovasc Surg. 2004;128:535-42.

5. Gaynor SL, Schuessler RB, Bailey MS, et al. Surgical treatment of atrial fibrillation: predictors of late recurrence. J Thorac Cardiovasc Surg. 2005;129: 104-11.

6. Voeller RK, Bailey MS, Zierer A, et al. Isolating the entire posterior left atrium improves surgical outcomes after the Cox maze procedure. J Thorac Cardiovasc Surg. 2008;135:870-7.

7. Melby SJ, Zierer A, Lubahn JG, et al. Normal quality of life after the Cox maze procedure for atrial fibrillation. Innovations (Phila). 2008;3:142-6.

8. Melby SJ, Zierer A, Bailey MS, et al. A new era in the surgical treatment of atrial fibrillation: the impact of ablation technology and lesion set on procedural efficacy. Ann Surg. 2006;244:583-92.

9. Schaff HV, Dearani JA, Daly RC, Orszulak TA, Danielson GK. Cox-Maze procedure for atrial fibrillation: Mayo Clinic experience. Semin Thorac Cardiovasc Surg. 2000;12:30-7.

10. McCarthy PM, Gillinov AM, Castle L, Chung M, Cosgrove D 3rd. The CoxMaze procedure: the Cleveland Clinic experience. Semin Thorac Cardiovasc Surg. 2000;12:25-9.

11. Millar RC, Arcidi JM Jr, Alison PJ. The maze III procedure for atrial fibrillation: should the indications be expanded? Ann Thorac Surg. 2000;70:1580-6.

12. Kamata J, Kawazoe K, Izumoto $H$, et al. Predictors of sinus rhythm restoration after Cox maze procedure concomitant with other cardiac operations. Ann Thorac Surg. 1997;64:394-8.

13. Kobayashi J, Kosakai Y, Nakano K, Sasako Y, Eishi K, Yamamoto F. Improved success rate of the maze procedure in mitral valve disease by new criteria for patients' selection. Eur J Cardiothorac Surg. 1998;13:247-52.

14. Gillinov AM, Sirak J, Blackstone EH, et al. The Cox maze procedure in mitral valve disease: predictors of recurrent atrial fibrillation. $J$ Thorac Cardiovasc Surg. 2005;130:1653-60.

15. Byrd GD, Prasad SM, Ripplinger CM, et al. Importance of geometry and refractory period in sustaining atrial fibrillation: testing the critical mass hypothesis. Circulation. 2005;112(suppl I):I7-13. 
16. Oral H, Scharf C, Chugh A, et al. Catheter ablation for paroxysmal atrial fibrillation: segmental pulmonary vein ostial ablation versus left atrial ablation. Circulation. 2003;108:2355-60.

17. Pappone C, Oreto G, Rosanio S, et al. Atrial electroanatomic remodeling after circumferential radiofrequency pulmonary vein ablation: efficacy of an anatomic approach in a large cohort of patients with atrial fibrillation. Circulation. 2001; 104:2539-44

18. Ishii Y, Gleva MJ, Gamache MC, et al. Atrial tachyarrhythmias after the maze procedure: incidence and prognosis. Circulation. 2004;110(suppl II):II164-8.

19. Ishii Y, Schuessler RB, Gaynor SL, et al. Inflammation of atrium after cardiac surgery is associated with inhomogeneity of atrial conduction and atrial fibrillation. Circulation. 2005;111:2881-8.

20. Edgerton JR, McClelland JH, Duke D, et al. Minimally invasive surgical ablation of atrial fibrillation: six-month results. J Thorac Cardiovasc Surg. 2009;138:109-14.

\section{Discussion}

Dr Michael Argenziano (New York, $N Y$ ). My disclosure is that I am a consultant for Estech.

Ralph, you and your group need to be congratulated for another outstanding presentation in the area of atrial fibrillation, and you have certainly carried on Dr Cox's tradition at St. Louis very well. Thank you for the manuscript in advance, as that was obviously very helpful.

As you noted, the Cox maze procedure was really the gold standard and really remains the gold standard for the treatment of atrial fibrillation; however, it was never adopted in any sorts of great numbers because of its complexity. As you know, since the late 1990s, a number of more "limited" procedures using a variety of energy sources have been developed and, unfortunately, there have been many energy sources, many lesion sets, many selection criteria, and many definitions of success, et cetera, to the point that, although we have been doing this for over 10 years, many questions remain. Those are, what are the best energy sources? Are there certain energy sources that are better in certain applications than others? What are the better lesion sets? Should we be using a box versus an isolated pulmonary vein approach? Should we be doing left atrium only or both atria, as you did here? How do we select patients? And then, most importantly, I believe, how do we follow these patients up? Because although you did a tremendous job in following up these patients, the total percentage of the time that these patients are alive that you have monitored is really very small, and especially because you have such a high paroxsymal A-fib component, how do we know what these patients are doing when they are not being monitored?

Your findings in a large group of patients with atrial fibrillation, which were a mix of both paroxsymal and nonparoxysmal patients but which were mostly condominant, were that a box lesion is better, and I certainly would agree with that, and we have been saying for years and many of us have been saying that a box lesion just electrophysiologically makes more sense, because not only does it eliminate the triggers of atrial fibrillation that occur within the pulmonary veins but it also acts to compartmentalize the left atrium and reduce the ability of the substrate to contribute, as Dr Cox taught us.

You found that a large left atrium is worse, and we concur with that and we have actually published that as well, and it makes good sense that probably the best surrogate of the degree of remodeling that exists in an atrium is not duration or anything else or age but rather the size of the atrium.
And then, finally, you found that early arrhythmias predicted a worse outcome, which actually was a surprise to us, because we looked at this as well and we actually have found that there is no difference and, for that reason, have not really been very aggressive about managing the early arrhythmias, although I would like to hear more from you about that.

So, you had excellent overall success. You used right-sided lesions universally, which we would agree with, and, again, you had excellent follow-up. I have 3 questions for you.

First is, you have shown that the box lesion is better, but we know that the majority of the patients that you operated on in this series were concomitant, although a third were stand-alone procedures. You and I have spoken before, and I know that you have done many more than 95 stand-alone atrial fibrillation ablations. So, therefore, you must be doing some of the standalone patients with lone atrial fibrillation with a purely epicardial pulmonary vein bipolar clamp technique. If so, how did you choose those patients and why did the patients in this series get a more extensive lesion set?

Dr Damiano. That is an excellent question. Just to be as quick as possible, we have done a significant number of the epicardial approaches. We favor the bipolar clamps, and that has been most of our experience. We initially performed the procedure on a wide group of patients, though we have had, like others, poor results in patients with persistent or long-standing atrial fibrillation. We are no longer offering this operation to this group because of the poor results. And, to be honest with you, we cannot find any device in our research laboratory capable of making reliable linear lesions on the beating heart. I do not think there is one on the market right now. However, we are initiating some hybrid approaches with our electrophysiologists to help us overcome some of these shortcomings. At present, we would consider patients with paroxysmal atrial fibrillation and a left atrial diameter of less than $5 \mathrm{~cm}$ as good candidates for pulmonary vein isolation done thoracoscopically or with small incisions. Our success rates have not been quite as high as with a full Maze procedure. The last time we looked, it was about $75 \%$. This is not bad, and you could view it as part of a staged procedure. So we do offer that.

We give our patients full informed consent. We let them look at our published results and our database results and let them choose between the procedures. As we both know, some patients go for a minimally invasive approach and some patients, particiularly if they have failed a number of catheter ablations, just want to be cured and they will go for a more complete procedure. You can do the full maze IV, similar to our previous discussion, through a right minithoracotomy. It is a lot easier than doing mitral valve repair and with present devices it can be done very well. I agree, you have to tailor your procedure to each specific patient.

I would caution those people who are doing epicardial pulmonary vein isolation as their only procedure for atrial fibrillation to be very careful that the patient's arrhythmia is not actually atrial flutter. This is quite common in failed catheter ablations, which now make up over half of our stand-alone experience. You should study them or make sure you have a qualified physician review their EKGs and Holter monitors. Because if they have recurrent flutter, which is not unusual, the only operation you can do is a complete Maze procedure.

Dr Argenziano. I would agree with that. And, in fact, at Columbia we have for at least a few years now actually not offered a purely 
epicardial operation to patients with either multiple failed ablations, enlarged atria, poor ejection fraction, and we reserve that really to the purely early paroxsymal patients, which, unfortunately, are exceedingly fewer and fewer because of the success of catheter ablation.

Two brief questions. If earlier tachyrhythmias in the perioperative period are a predictor of failure, what are you doing to either treat that or to study those patients? In other words, do you think that early arrhythmias predict failure because atrial fibrillation in the perioperative period begets atrial fibrillation or do you think that early atrial fibrillation is simply a surrogate for incomplete lesions?

Dr Damiano. That is an excellent question, Mike, and I can't really answer it. As you know, we published in Circulation in 2005 our maze III experience in which early arrhythmias were not a predictor of late failure. It has turned out to be a predictor in this study, and the only thing I can tell you is we now have a much stricter definition of failure in that any patients who were on antiarrhythmic drugs were considered a failure. So we have established a more strict definition and perhaps that is allowing us some more discriminatory ability.

My own feeling is it is not an incomplete lesion set, and we, like I am sure you do, test for conduction block. The pulmonary vein isolation is tested in every patient we are able cardiovert, which is over $90 \%$ of this patient cohort. I think that early arrhythmias are a marker of a worse atrial substrate, probably increased atrial fibrosis. We are doing a lot sicker patients and, like you say, I completely agree, left atrial diameter is a really good surrogate for atrial remodeling. As I have thought about this more, I am not even sure that being aggressive with atrial reduction will be enough in some of these patients. There is a group of patients that I am convinced we shouldn't probably be operating on because of end-stage atrial myopathy. In terms of restoring sinus rhythm, we are pretty aggressive. We usually delay early cardioversion, but at 1 month we aggressively attempt to restore sinus rhythm in all of those patients.

Dr Argenziano. The last question is about follow-up, and that really I think winds up being the most interesting part of this entire area. As you know, the Cardiothoracic Surgery Trials Network, which is an NIH network grant, is currently involved in a randomized study looking at atrial fibrillation ablation, and one of our main interests in that trial is really to figure out how can we improve the way that we follow up these patients. How can we calculate not just things like incremental A-fib incidents but rather things like atrial fibrillation burden? And so what do you think about implantable devices and transtelephonic monitoring and ways to even increase even the excellent follow-up that you have?

Dr Damiano. I think that is an excellent point and a relatively unanswered question. We have looked at our data and when we eliminated the patients who just had ECG follow-up, it did not impact the success rate. Unfortunately, the ECG follow-up group was generally in the early part of our series when we did the nonbox lesion, so it may have confounded the analysis.

I agree with you, monitoring remains a big question mark. I do feel an EKG alone is not adequate in 2010. We are presently starting a clinical trial with the Reveal device by Medtronic, which is an implantable device, which would allow you almost continuous monitoring. The question is how valuable this is going to be. What if a patient has a minute of atrial fibrillation in a month? What should we do about that? I think it is going to make management interesting.

I think that is something that I hope the NIH trial answers and, as we gain more experience with these new implantable devices, we may be able to understand exactly what the right thing to do is.

Dr Argenziano. Congratulations on a great study, Ralph.

Dr Richard Shemin (Los Angeles, Calif). Another major contribution to the outcomes and work that you have done at Wash $\mathrm{U}$ for A-fib. Obviously, we all agree that transmurality is important. I think you just mentioned that in over $90 \%$ of the cases you do intraoperative testing.

A technical question: How many times do you have to reapply the clamp a second or a third time?

Dr Damiano. We were one of the first groups to put out a word of caution that we occasionally required 8 or 9 clamp applications to isolate the pulmonary veins with the early versions of some of these bipolar devices. With the 2 present versions, the Medtronic Cardioblate and the AtriCure Synergy clamps we found, that both have excellent results. In general, I would say that they are over $90 \%$ effective with a single ablation when judged by the creation of conduction block. We are in a clinical trial with 1 of the devices where we are testing this question. While I haven't seen the multicenter data, our own data has shown an over $95 \%$ success rate in creating conduction block with a single ablation, but it is not $100 \%$.We do 2 ablations for every lesion and then test by pacing from each pulmonary vein. One of the reasons we don't have data in all patients for exit and entrance block is that we have a number of patients who either have a left atrial thrombus, which I would not recommend cardioversion because of the potential for emboli, or in whom we are unable to restore sinus rhythm with cardioversion.

Dr Shemin. Since early recurrence of atrial fibrillation or other arrhythmias is an adverse predictor, what is your specific postoperative protocol as far as antiarrhythmic drugs and early cardioversion?

Dr Damiano. We have not changed any of our protocols based on the results of this study, at least at the present time. Every patient that comes out of surgery, once they restore their sinus rhythm is started on antiarrhythmic drug. Our drug of choice is amiodarone or whatever drug they tolerated preoperatively, and we continue that for 2 months.

We have been aggressive with cardioversion, but ideally we usually delay cardioversion for 3 to 4 weeks to let all the inflammation subside. We found, as opposed to postoperative atrial fibrillation in patients undergoing $\mathrm{CABG}$ for instance, a lot of these patients do not respond to early cardioversion. If it is not successful, it can be upsetting to the patient.

When we see the patients back in a month, if they are in an atrial flutter or fibrillation we will arrange cardioversion. I arrange it myself. I don't leave it up to the referring cardiologist.

Dr Shemin. Final question: Is there any role for the Cox maze III procedure?

Dr Damiano. We talked about that in the panel, and at our institution right now, no, I don't see any role for it.

Dr Thorsten Hanke (Luebeck, Germany). Congratulations on your results. Just one question. Your more intensified monitoring, that was about $25 \%$ of the patients?

Dr Damiano. Seventy percent of the entire population had either 24-hour Holters or more prolonged monitoring. After 2006, 
when the guidelines were actually published, $94 \%$ of patients had prolonged monitoring.

As many of you know, if you follow large numbers of patients with atrial fibrillation, it is hard enough to get them to come back. It can be harder and harder as you try to get longer periods of monitoring. But, yes, the majority of patients here had prolonged monitoring.

Dr Hanke. Did you see any difference with your more prolonged observations than with the short-term ones? And keep in mind that, even with a 14-day Holter strategy, you only have a sensitivity of about 69 to $70 \%$. So don't you think it is time for continuous monitoring, never mind whether it is Medtronic, Biotronic, whatsoever, for all the patients?

Dr Damiano. I think it is an excellent point and to truly define failure rates we will need to use such devices. But, as you know, certainly at least in the United States, there have not been small implantable devices available until recently and the reimbursement has been a problem. So it has not been a viable option. But I agree, and we will learn a lot from continuous monitoring.

However, as I said in my previous comment, if you took out from our series the patients who had ECG only, using prolonged monitoring did not result in a significant change in our failure rate. However, I totally agree with you, and there are certainly a number of studies in the electrophysiology literature and a few from our literature that would suggest that, the more you monitor, the more arrhythmias you will discover.

I will just put a note of caution for those of you who follow these patients. We are following over 500 to 600 patients right now, and what we would do with continuous monitoring in 500 patients. An army of people would need to deal with all this data. There may be medicolegal issues if, for instance, a patient had a 1-minute episode of atrial fibrrillation and we didn't do anything but we happen to have the electrograms stored in some computer warehouse. It is not a trivial process. We are wrestling with what we are going to do with this mountain of data. We will need some help with it. But I totally agree with your point there, and I think it will be an advance.

Dr Masashi Komeda (Kyoto, Japan). Congratulations on a beautiful study. As you mentioned, left atrial diameter is so important. We did a study of atrial reduction, Cox maze III proce- dure, and we published the data from JTCVS twice. When we did a volume reduction one third as big as before the surgery, the defibrillation rate was quite high. I want to share your comment on that.

Dr Damiano. I am aware of your excellent work and certainly in my conclusions mention that we need to maybe adapt a more aggressive atrial reduction procedure in patients with large left atria to improve our success rates. We also may need a more extended lesion set.

I will tell you, there is a subset of those patients that probably no matter what you do, you won't be able to cure them. They have remodeled their atrium and they are so fibrotic that really no amount of reduction will work. Dr Madison Spach at Duke showed that in elderly patients with atrial fibrosis that they can maintain atrial fibrillation in a single trabeculae crossing the right atrium. These patients we shouldn't operate on, and perhaps MRI or body surface mapping may help us identify this substrate before the operation. But I acknowledge your work, and we are going to try a little more aggressive reduction procedure in the future, similar to what you have published.

Dr Komeda. Thank you. About that issue, maybe you are right for some patients, but for some others, interestingly, the left atrium keeps shrinking 1 year after surgery; it just keeps shrinking. So maybe some patients still have a chance to have that type of reverse remodeling and a better outcome of defibrillation.

Dr Damiano. I agree with you. It is trying to discriminate who is going to get better and who isn't. That would be very helpful before we put them through this surgery.

Dr Marco Zenati (Pittsburgh, $\mathrm{Pa}$ ). I enjoyed your presentation and congratulations, especially for bravely adopting the guidelines for both efficacy and follow-up. My question about the intensity of the follow-up was already answered. I just want to make a brief comment about the fact that your outcomes are based on a single procedure and, if the guidelines were meant to compare surgical versus catheter ablations, it is important that we compare single procedures to single procedures.

Dr Damiano. I agree completely, but you need to be talking to electrophysiologists, not me. They never like to do that. 